\title{
Species Diversity and Flagellate Infections in the Sand Fly Fauna near Porto Grande, State of Amapá, Brazil (Diptera: Psychodidae. Kinetoplastida:Trypanosomatidae)
}

\author{
Rui A Freitas, Roberto D Naiff, Toby V Barrett ${ }^{+}$
}

\author{
Grupo de Biologia Vetorial e Eco-epidemiologia de Trypanosomatidae na Amazônia, Coordenação de Pesquisas em Ciências da
} Saúde, Instituto Nacional de Pesquisas da Amazônia, Caixa Postal 478, 69011-970 Manaus, AM, Brasil

Forty-six species of Lutzomyia and one species of Brumptomyia were identified among 20,008 sand flies collected in central Amapá. L. squamiventris maripaensis, L. infraspinosa, L. umbratilis and L. ubiquitalis accounted for $66 \%$ of the specimens caught in light traps, and L. umbratilis was the commonest of the 16 species found on tree bases. Seven species of Lutzomyia including L. umbratilis were collected in a plantation of Caribbean pine. Sixty out of 511 female sand flies dissected were positive for flagellates. Among the sand flies from which Leishmania was isolated, promastigotes were observed in the salivary glands and foregut of 13 out of 21 females scored as having very heavy infections in the remainder of the gut, reinforcing the idea that salivary gland invasion may be part of the normal life cycle of Leishmania in nature. Salivary gland infections were detected in specimens of L. umbratilis, L. whitmani and L. spathotrichia. Parasites isolated from L. umbratilis, L. whitmani and also from one specimen of L. dendrophyla containing the remains of a bloodmeal, were compatible with Le. guyanensis by morphology and behaviour in hamsters.

Key words: Phlebotominae - diversity - distribution - Leishmania - salivary glands - Amapá - Brazil

The phlebotomine sand fly fauna of the Brazilian State of Amapá has been poorly studied in comparison with neighbouring areas of the State of Pará and French Guyana (Brazil et al. 2000). Most of the sand fly distribution maps in Young and Duncan (1994) are blank for this part of Brazil, even though cutaneous leishmaniasis has long been recognized as an important public health problem in the former Federal Territory (Lainson \& Shaw 1973). In this field report the faunistics of sand fly samples collected mainly along the Perimetral Norte highway (BR-210) are analyzed. The eastern end of this uncompleted highway runs west from the town of Porto Grande through lowland rainforest in the lower Amapari basin. According to Backus et al. (1991) this part of the highway lies in area 59 (Araguari) which they describe as the nucleus of the Oyapock centre of endemism.

Although invasion of the vectors' salivary glands by promastigotes is not currently thought to be a necessary stage in the transmission of Leishmania by bite, the phenomenon has been reported in both naturally infected (Arias \& Freitas 1978, Naiff et al. 1991) and experimentally infected sand flies (Killick-Kendrick et al. 1996). There have hitherto been so few of such observations that some workers may be reluctant to accept that invasion of the salivary glands is a normal part of the life cycle of Leishmania. The presence of large numbers of infected Lutzomyia umbratilis concentrated on the bases of trees in forest north of the Amazon River provides an opportunity to reexamine this question. In the present report we show that the prevalence of natural infection of Lutzomyia salivary

\footnotetext{
Financed by the Pilot Programme for the Protection of Brazilian Rainforest/MCT - Subprograma C\&T/PPD G-7

${ }^{+}$Corresponding author. Fax: +55-92-643.3061. E-mail: tbarrett@inpa.gov.br

Received 4 May 2001

Accepted 16 August 2001
}

glands by promastigotes, presumably of Leishmania, may be much higher than was previously suspected.

\section{MATERIALS AND METHODS}

Study areas - Most of the material was collected in primary terra-firme lowland rainforest at $\mathrm{km} \mathrm{7,} \mathrm{km} 17$ and $\mathrm{km} 57$ (from the town of Porto Grande) along the BR-210 highway. The site at $\mathrm{km} 7$ is $1 \mathrm{~km}$ north of the highway at Recanto Ecológico Sonho Meu, where collections were made along a tourist trail rising into the forest. At km 17 traps were set in the forest on high ground near the edge of the highway. The site at $\mathrm{km} 57$ is Assentamento Munguba, near $00^{\circ} 43^{\prime} \mathrm{N} 051^{\circ} 53^{\prime} \mathrm{W}$; about $5 \mathrm{~km}$ south of the BR-210. This is a community of 28 households participating in a government sponsored (Incra) settlement programme. The vegetation was still relatively undisturbed apart from the access road itself and a clearing corresponding to the main villa. Leishmania isolates IM-4677, IM4678 and IM-4679 cultured from skin lesions from three of the settlers are compatible with Le. guyanensis by morphology and behaviour in hamsters.

The final site (BR-156: $\mathrm{km} \mathrm{16}$ ) is $16 \mathrm{~km}$ southeast of Porto Grande on the highway to Macapá, about $300 \mathrm{~m}$ from the edge of the road. Light traps were set in a mature stand of Caribbean pine (Pinus caribeae var. hondurensis) part of an extensive monocultural plantation distant from any trace of the native forest.

Sampling - CDC miniature light traps were suspended at approximately $1 \mathrm{~m}$ from the ground. Tree-base samples were obtained by aspiration of the trunk with a hand-held CDC light trap. Human bait catches were carried out by four collectors between $18.00 \mathrm{~h}$ and $19.00 \mathrm{~h}$. All specimens collected on human bait were dissected. No attempt was made to select specimens from tree-base samples randomly for dissection, and the material dissected is probably biased in favour of fed and gravid females. Collectors: RAF, RDN and Francisco Lima Santos (Inpa), 28 October-9 November 1999.

Diversity parameters - In the Tables, alpha diversity is the Fisher-Williams index, which is $\alpha$ in the expression $S=$ 
$\alpha \ln (1+\mathrm{N} / \alpha)$ where $\mathrm{S}$ is the total number of species in the sample and $\mathrm{N}$ is the number of individuals. In light trap samples abundance is expressed as the mean number of individuals per trap per night. Dominance is the number of individuals of the most abundant species divided by $\mathrm{N}$.

Detection and isolation offlagellates - Sand flies were placed in a drop of saline on a microscope slide and the head separated from the thorax with a pair of needles, before drawing out the abdominal and thoracic gut through the apex of the abdomen. In these preparations the salivary glands and most of the foregut usually accompany the head, and the diverticular crop of the foregut accompanies the midgut. The mid and hindgut were examined first, and only if these presented heavy infections was the head examined for flagellates. Positive guts were transferred to tubes of NNN blood-agar culture medium. Unfortunately, these ran out just before the infected $L$. spathotrichia was detected. Positive cultures were subsequently inoculated intradermally in hamsters.

Material examined - Female sand flies dissected for parasitological examination were preserved in gum-chloral on the original microscope slides. Undissected specimens were cleared in sodium hydroxide and phenol for identification and are at present stored in $70 \%$ ethanol in our laboratory. Leishmanial isolates cryopreserved in liquid nitrogen will be deposited in the Inpa culture collection (curator: Maricleide F Naiff, CPCS-Inpa).

\section{RESULTS}

Summaries of the sand fly samples are presented in Tables I-IV and Figs 1-2. Two males of the migonei species group, compatible with Fig. 66 of Young and Duncan (1994) are provisionally associated with the females of the informally named Lutzomyia sp. de Baduel (Floch \& Abonnenc). L. squamiventris maripaensis was the most abundant species in the light trap samples $(26 \%)$ and on human bait (84\%). L. umbratilis was the most abundant species on tree bases $(87 \%)$ and the third most abundant species in the light trap samples (14\%). Species richness and diversity were unremarkable for the Amazon Region, with a total of 46 species among 6,033 individuals captured in light traps. Catches were high, particularly at $\mathrm{km} 7$ where an

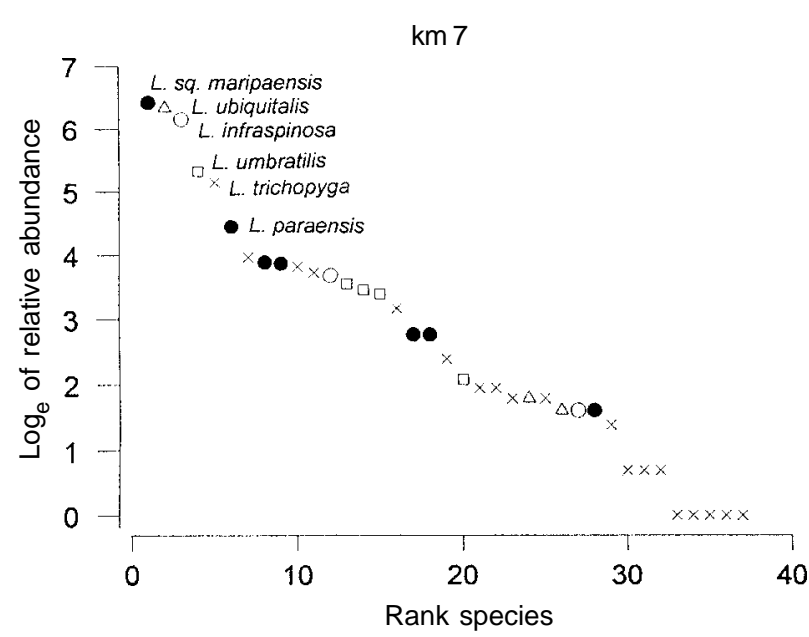

Fig. 1: diversity diagram (natural logarithm of realtive abundance on rank) for Lutzomyia species in light-trap samples at BR-210, km 7 (Recanto Ecológico), Amapá. O: L. (Psychodopygus) sp.; $\triangle$ : L. (Trichophoromyia) sp.; O:L. (Evandromyia) sp.; $\square: L$. (Nyssomyia) sp.; x: other species. See Table IV for crude data and diversity statistics.

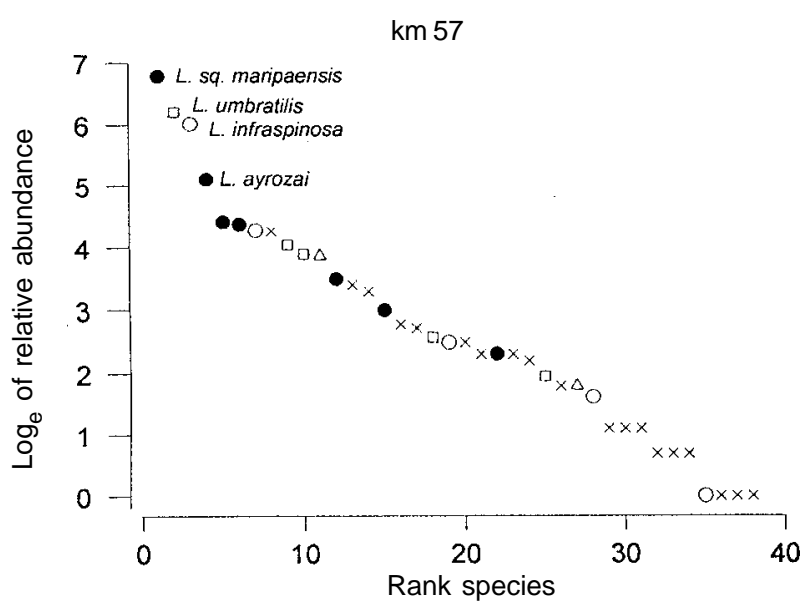

Fig. 2: diversity diagram (natural logarithm of relative abundance on rank) for Lutzomyia species in light-trap samples at BR-210, km 57 (Assentamento Munguba), Amapá. Symbols as in Fig. 1. Additional data in Table IV.

average of 132 individuals were captured per trap-night. Phlebotomines were very abundant on tree bases at $\mathrm{km} 57$, where 13,499 specimens including 11,964 L. umbratilis were taken by a single collector in about an hour and a half. The 15 traps set for one night in the Pinus plantation caught 11 sand flies of seven species, including male and female L. umbratilis (Table IV).

Of the 511 female sand flies dissected, 60 were positive for flagellates (Table V). Of the positive flies, 56 were $L$. umbratilis from tree bases, two were $L$. dendrophyla from tree bases, one was L. whitmani from a CDC trap at BR-210 $\mathrm{km} \mathrm{17}$, and one was L. spathotrichia from a tree base at km 57. Of the 56 positive $L$. umbratilis, 55 were from $\mathrm{km} 57$, equivalent to an infection rate of $30 \%$ for tree-base $L$. umbratilis dissected at this site.

Of the positive flies from which we did not succeed in cultivating flagellates, the L. spathotrichia was infected with parasites of similar appearance in vivo to those in $L$. umbratilis females from which Leishmania was isolated. One L. umbratilis female without a bloodmeal had a moderate infection in the anterior and posterior midgut, with parasites tentatively identified in vivo as Trypanosoma sp.

Parasites were cultured from 40 Lutzomyia females (Table VI). All of these isolates contained Leishmania confirmed by hamster inoculation and are compatible with $L e$. guyanensis by morphology and behaviour in hamsters. The primary culture from $L$. dendrophyla also contained fusiform promastigotes thought to be Endotrypanum sp. and which probably correspond to the parasites observed in the Malpighian tubules (cf. Franco et al. 1997).

Salivary gland infections were recorded in 18 of the 60 positive flies dissected, including $L$. umbratilis, $L$. whitmani and L. spathotrichia (Table V). In flies from which Leishmania was isolated, salivary gland and foregut infections were observed in 13 out of 21 females (62\%) with heavy (++++) infections of the abdominal and thoracic gut (Table VI).

\section{DISCUSSION}

The present survey supplements a list of 18 species of Lutzomyia from lowland Amapá (Brazil et al. 2000) and a preliminary report on an apparently more diverse 
phlebotomine fauna from the Serra do Navio area (Souza et al. 2001). Many of the species listed here were previously known from French Guyana and/or Pará in Brazil, but our records represent significant extensions of the known distribution particulary for $L$. evangelistai, $L$. damascenoi, L. ininii (first record for Brazil), L. williamsi, $L$. dreisbachi and $L$. chassigneti. The records of $L$. squamiventris maripaensis and L. yuilli pajoti help fill the gap between the known northern and southern localities of these taxa. Species common in collections from Amazonas and western Pará and conspicuous by their absence from the present samples include L. olmeca nociva, L. chagasi and L. carrerai. These species are also absent from the known fauna of French Guyana.
The recently described Lutzomyia campograndensis Oliveira, Andrade Filho, Falcão \& Brazil 2001 is known to occur in Amapá (Oliveira et al. 2001) and may be represented among the four specimens we have identified as $L$. lutziana. These two species are so similar morphologically that at present we are unable to separate them confidently on the basis of the published descriptions alone.

L. umbratilis, a vector of Le. guyanensis, was previously thought to be incapable of adapting to pine plantations (Lainson 1988). Our finding of L. umbratilis and other species in this anthropic environment may be related to the age of the plantation and the presence of deer and other mammals feeding on the seeds of the mature trees.

\section{TABLE I}

List of Phlebotominae collected, Porto Grande (Amapá) 28 Oct.-8 Nov. 1999

\begin{tabular}{|c|c|}
\hline Species & No. specimens \\
\hline \multicolumn{2}{|c|}{ 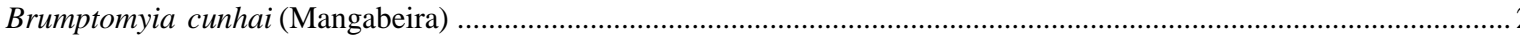 } \\
\hline \multicolumn{2}{|c|}{ 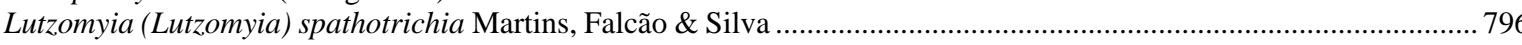 } \\
\hline \multicolumn{2}{|c|}{ 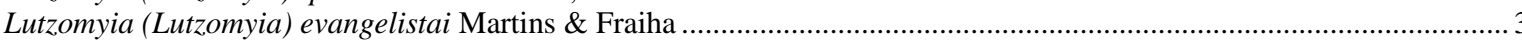 } \\
\hline \multicolumn{2}{|c|}{ 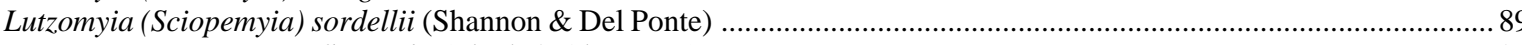 } \\
\hline \multicolumn{2}{|c|}{ 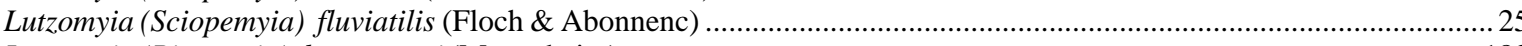 } \\
\hline \multicolumn{2}{|c|}{ 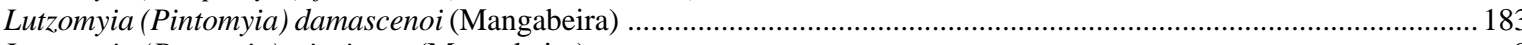 } \\
\hline \multicolumn{2}{|c|}{ 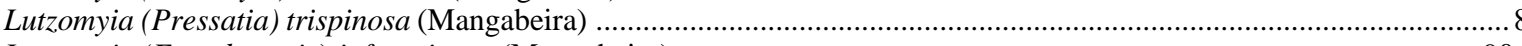 } \\
\hline \multicolumn{2}{|c|}{ 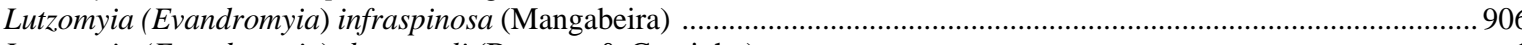 } \\
\hline \multicolumn{2}{|c|}{ 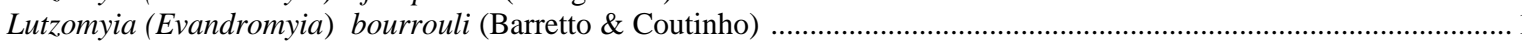 } \\
\hline \multicolumn{2}{|c|}{ Lutzomyia (Evandromyia) inpai Young \& Arias } \\
\hline \multicolumn{2}{|c|}{ 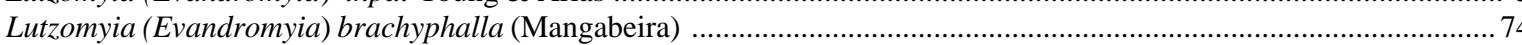 } \\
\hline \multicolumn{2}{|c|}{ 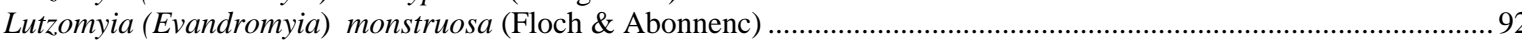 } \\
\hline \multicolumn{2}{|c|}{ 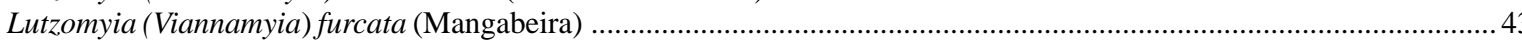 } \\
\hline \multicolumn{2}{|c|}{ Lutzomyia (Viannamyia) tuberculata (Mangabeira) } \\
\hline \multicolumn{2}{|c|}{ Lutzomyia (Psathyromyia) lutziana (Costa Lima) } \\
\hline \multicolumn{2}{|c|}{ 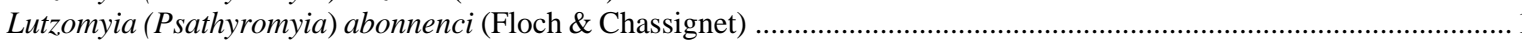 } \\
\hline \multicolumn{2}{|c|}{ 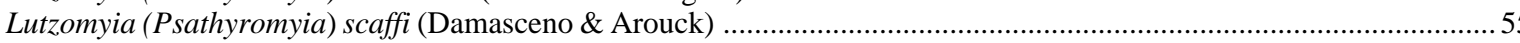 } \\
\hline \multicolumn{2}{|c|}{ 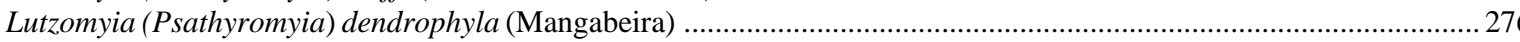 } \\
\hline \multicolumn{2}{|c|}{ 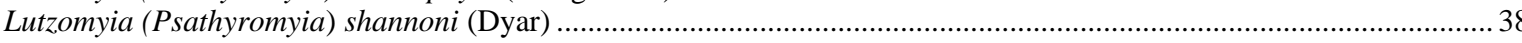 } \\
\hline \multicolumn{2}{|c|}{ 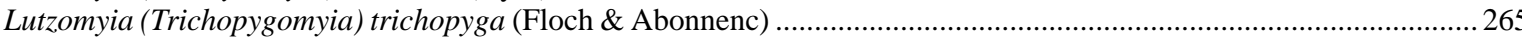 } \\
\hline \multicolumn{2}{|c|}{ 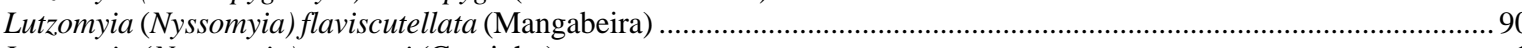 } \\
\hline \multicolumn{2}{|c|}{ 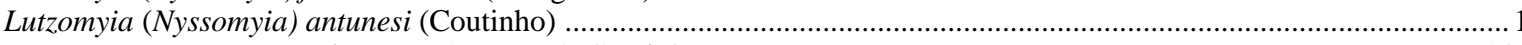 } \\
\hline \multicolumn{2}{|c|}{ 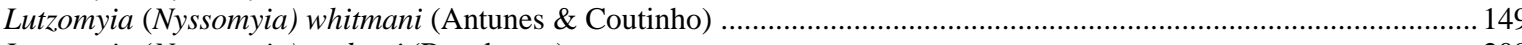 } \\
\hline \multicolumn{2}{|c|}{ 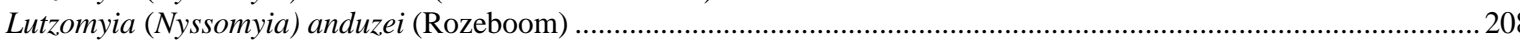 } \\
\hline Lutzomyt & ................ 12,876 \\
\hline Lutzomyt & \\
\hline Lutzom & ..................648 648 \\
\hline Lutzom & .... 13 \\
\hline Lutzomyt & ..................... 11 \\
\hline Lutzomyt & ……......... 1,670 \\
\hline Lutzomyt & ....................139 \\
\hline Lutzomyt & .....................39 \\
\hline Lutzomyt & \\
\hline Lutzomyt & \\
\hline Lutzomyt & \\
\hline Lutzomyt & 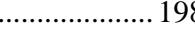 \\
\hline Lutzomyt & .................... \\
\hline Lutzomyt & …............ \\
\hline Lutzomyt & \\
\hline Lutzomy & \\
\hline Lutzomy & \\
\hline Lutzomyt & \\
\hline Lutzomyt & ......................... \\
\hline Lutzomyt & \\
\hline Lutzomyt & 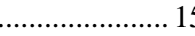 \\
\hline Lutzomyt & 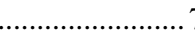 \\
\hline Lutzomyt & \\
\hline
\end{tabular}

$a$ : this species has not been previously reported in Brazil. Total species: Brumptomyia 1; Lutzomyia 46. Total individuals: 20,008 
Le. guyanensis has previously been isolated in the Jari area of Pará, approximately $180 \mathrm{~km} \mathrm{SW}$ of the present study area, from L. umbratilis, L. whitmani and L. anduzei by Ryan et al. (1987). One out of six L. spathotrichia in that collection was also infected with flagellates, but these were apparently not isolated or identified. L. spathotrichia is classified in the subgenus Lutzomyia, not known for including vectors of Le. guyanensis, but L. gomezi in the same cruciata Series is suspected as a vector of the closely related Le. panamensis (see Christensen et al. 1983). Our finding of L. spathotrichia with promastigotes in the mouthparts and salivary glands suggests that further attention to this anthropophilic (Young \& Duncan 1994) and locally abundant (Table II) species as a possible vector of Le. guyanensis could be rewarding.

The isolate IM-4685 from L. dendrophyla has now been confirmed as Le. guyanensis by enzyme electrophoresis (AR Franco, unpublished observations). The leishmanial parasites may however have been confined to the remains of the bloodmeal in the anterior midgut, and we do not suggest that $L$. dendrophyla is likely to be a natural host of this parasite.

In Table VI, the combinations of absent or fresh bloodmeals with medium development of the ovarioles observed in L. umbratilis suggest that gonadotrophic concordance may not always be simple (one bloodmeal per oviposition) in this species, and that at least some of these females required a second bloodmeal for egg maturation. Ingestion of a second bloodmeal has been shown to influence the distribution of promastigotes of $L e$. amazonensis and Le. mexicana in L. evansi under laboratory conditions (Vivenes et al. 2001).

Evidence exists for at least two mechanisms for the transmission of Leishmania by bite in the absence of invasion of the vectors' salivary glands (Killick-Kendrick 1979, Schlein et al. 1992). However, Killick-Kendrick et al. (1996) obtained experimental salivary gland infections in Phlebotomus duboscqi that had been allowed to feed on a suspension of Le. (Le.) tropica amastigotes. Promastigotes in the salivary glands of wild sand flies had previously been reported for $L$. anduzei and $L$. umbratilis infected with Le. guyanensis and in a female of the L. shannoni species group (subgenus Psathyromyia) infected with uncharacterised parasites (Arias \& Freitas 1978) as well as in $L$. sq. squamiventris infected with Le. (V.) naiffi (see Naiff et al. 1991).

Failure to detect salivary gland infections in wild sand flies is only meaningful in relation to the number of glands examined and the overall infection rates in the samples of sand flies dissected; and the scarcity of positive reports may be due in part to the difficulty of finding naturally infected females in many Leishmania/vector systems. As all of the reports of natural salivary gland infections are from the same group at Inpa, Killick-Kendrick et al. (1996) were understandably cautious when concluding that invasion of the salivary glands could, conceivably, be a normal part of the life cycle of Leishmania. Independent confirmation of the phenomenon, if possible supported by electron microscopy of thin sections of naturally infected flies, would therefore be of great interest. In Brazil, abundant material for study can be found on tree bases in terrafirme rainforest north of the Amazon River, from Amapá to Manaus.

\section{TABLE III}

Female Lutzomyia taken on human bait. Rodovia Perimetral Norte km 7 and km 17 (Porto Grande, Amapá, 28, 29 October 1999, 18:00-19:00 h)

\begin{tabular}{lc}
\hline Species & No. specimens \\
\hline Lutzomyyia sq. maripaensis & 77 \\
L. paraensis & 8 \\
L. h. hirsuta & 2 \\
L. ayrozai & 1 \\
L. infraspinosa & 3 \\
L. dendrophyla & 1 \\
\hline No. per man hour & 11.5 \\
\hline
\end{tabular}

TABLE II

Species composition of tree-base samples of Lutzomyia and Brumptomyia, Rodovia Perimetral Norte, Porto Grande (Amapá)

\begin{tabular}{|c|c|c|c|c|c|c|c|}
\hline \multirow[b]{2}{*}{ Species } & \multicolumn{2}{|c|}{$\mathrm{km} 7$} & \multicolumn{2}{|c|}{ km 17} & \multicolumn{2}{|c|}{$\mathrm{km} 57$} & \multirow[t]{2}{*}{ Total } \\
\hline & $G$ & $E$ & $G$ & $E$ & $G$ & $E$ & \\
\hline L. umbratilis & 17 & 17 & 20 & 9 & 7,697 & 4,267 & 12,027 \\
\hline L. anduzei & 0 & 0 & 0 & 0 & 65 & 54 & 119 \\
\hline L. whitmani & 0 & 0 & 2 & 3 & 13 & 22 & 40 \\
\hline L.y. pajoti & 0 & 1 & 0 & 0 & 26 & 7 & 34 \\
\hline L. spathotrichia & 1 & 1 & 0 & 0 & 606 & 144 & 752 \\
\hline L. dendrophyla & 2 & 4 & 0 & 0 & 197 & 62 & 265 \\
\hline L. scaffi & 2 & 1 & 0 & 0 & 35 & 14 & 52 \\
\hline L. shannoni & 0 & 0 & 0 & 0 & 30 & 5 & 35 \\
\hline L. rorotaensis & 30 & 8 & 171 & 40 & 48 & 14 & 311 \\
\hline L. damascenoi & 0 & 0 & 4 & 0 & 80 & 78 & 162 \\
\hline L. furcata & 0 & 0 & 1 & 1 & 7 & 12 & 21 \\
\hline L. tuberculata & 0 & 0 & 29 & 15 & 0 & 8 & 52 \\
\hline L. ubiquitalis & 0 & 0 & 2 & 0 & 4 & 0 & 6 \\
\hline L. davisi & 0 & 0 & 0 & 0 & 3 & 0 & 3 \\
\hline B. cunhai & 0 & $1 ?$ & 0 & 0 & 1 & 0 & 2 \\
\hline L. trichopyga & 0 & 0 & 0 & 2 & 0 & 0 & 2 \\
\hline Individuals & \multicolumn{2}{|c|}{85} & \multicolumn{2}{|c|}{299} & \multicolumn{2}{|c|}{13,499} & 13,883 \\
\hline Species & \multicolumn{2}{|c|}{7} & \multicolumn{2}{|c|}{8} & \multicolumn{2}{|c|}{15} & 16 \\
\hline
\end{tabular}


TABLE IV

Species composition of Lutzomyia from CDC light trap samples, Rodovia Perimetral Norte and BR-156 km 16 (Pinus), Porto

\begin{tabular}{|c|c|c|c|c|c|c|c|c|c|}
\hline \multirow[t]{2}{*}{ Species } & \multicolumn{6}{|c|}{ Grande (Amapá) } & \multicolumn{2}{|c|}{ Pinus } & \multirow[t]{2}{*}{ Total } \\
\hline & G & $\mathrm{E}$ & G & $\mathrm{E}$ & G & $\mathrm{E}$ & $\mathrm{G}$ & $E$ & \\
\hline L. sq. maripaensis & 322 & 294 & 25 & 66 & 370 & 514 & 0 & 2 & 1,593 \\
\hline L. infraspinosa & 223 & 251 & 6 & 11 & 242 & 170 & 0 & 0 & 903 \\
\hline L. umbratilis & 138 & 69 & 105 & 35 & 330 & 169 & 1 & 2 & 849 \\
\hline L. ubiquitalis & 311 & 259 & 14 & 10 & 34 & 14 & 0 & 0 & 642 \\
\hline L. trichopyga & 99 & 74 & 6 & 13 & 48 & 23 & 0 & 0 & 263 \\
\hline L. ayrozai & 11 & 5 & 2 & 14 & 123 & 42 & 0 & 0 & 197 \\
\hline L. rorotaensis & 38 & 15 & 86 & 27 & 12 & 18 & 0 & 0 & 196 \\
\hline L. h. hirsuta & 40 & 8 & 3 & 3 & 69 & 13 & 0 & 0 & 136 \\
\hline L. davisi & 30 & 19 & 2 & 6 & 35 & 44 & 0 & 0 & 136 \\
\hline L. paraensis & 47 & 39 & 4 & 3 & 6 & 14 & 0 & 0 & 113 \\
\hline L. whitmani & 23 & 12 & 15 & 46 & 6 & 7 & 0 & 0 & 109 \\
\hline L. monstruosa & 1 & 4 & 2 & 13 & 24 & 48 & 0 & 0 & 92 \\
\hline L. flaviscutellata & 8 & 24 & 2 & 7 & 24 & 25 & 0 & 0 & 90 \\
\hline L. sericea & 33 & 13 & 8 & 9 & 19 & 8 & 0 & 0 & 90 \\
\hline L. anduzei & 14 & 16 & 1 & 1 & 14 & 43 & 0 & 0 & 89 \\
\hline L. sordellii & 4 & 7 & 19 & 43 & 6 & 10 & 0 & 0 & 89 \\
\hline L. brachyphalla & 25 & 15 & 11 & 11 & 8 & 4 & 0 & 0 & 74 \\
\hline L. spathotrichia & 9 & 33 & 1 & 0 & 0 & 0 & 1 & 0 & 44 \\
\hline L. tuberculata & 2 & 22 & 12 & 5 & 0 & 3 & 0 & 0 & 44 \\
\hline L. claustrei & 3 & 2 & 0 & 0 & 28 & 5 & 1 & 0 & 39 \\
\hline L. amazonensis & 7 & 9 & 0 & 0 & 2 & 8 & 0 & 0 & 26 \\
\hline L. fluviatilis & 1 & 3 & 12 & 9 & 0 & 0 & 0 & 0 & 25 \\
\hline L.furcata & 0 & 7 & 2 & 1 & 2 & 10 & 0 & 0 & 22 \\
\hline L. damascenoi & 0 & 1 & 9 & 1 & 2 & 8 & 0 & 0 & 21 \\
\hline L. aragaoi & 3 & 4 & 0 & 1 & 7 & 3 & 0 & 2 & 20 \\
\hline L. y. pajoti & 4 & 4 & 1 & 1 & 4 & 3 & 0 & 0 & 17 \\
\hline L. dreisbachi & 0 & 0 & 0 & 0 & 7 & 8 & 0 & 0 & 15 \\
\hline L. brachipyga & 4 & 2 & 2 & 5 & 0 & 0 & 0 & 0 & 13 \\
\hline L. ininii & 5 & 0 & 0 & 0 & 4 & 2 & 0 & 0 & 11 \\
\hline L. dendrophyla & 1 & 1 & 0 & 1 & 3 & 3 & 1 & 0 & 10 \\
\hline L. serrana & 0 & 0 & 0 & 0 & 6 & 3 & 0 & 0 & 9 \\
\hline L. migonei & 3 & 3 & 0 & 1 & 0 & 1 & 0 & 0 & 8 \\
\hline L. trispinosa & 3 & 3 & 0 & 0 & 1 & 1 & 0 & 0 & 8 \\
\hline L. chassigneti & 0 & 2 & 1 & 3 & 0 & 1 & 0 & 0 & 7 \\
\hline L. inpai & 0 & 0 & 0 & 0 & 3 & 2 & 0 & 0 & 5 \\
\hline L. sp. de Baduel & 0 & 0 & 2 & 1 & 0 & 2 & 0 & 0 & 5 \\
\hline L. lutziana & 1 & 0 & 0 & 0 & 1 & 2 & 0 & 0 & 4 \\
\hline L. evangelistai & 0 & 1 & 0 & 2 & 0 & 0 & 0 & 0 & 3 \\
\hline L. pacae & 0 & 0 & 1 & 2 & 0 & 0 & 0 & 0 & 3 \\
\hline L. b. barrettoi & 0 & 0 & 0 & 0 & 2 & 1 & 0 & 0 & 3 \\
\hline L. scaffi & 2 & 0 & 0 & 0 & 0 & 1 & 0 & 0 & 3 \\
\hline L. shannoni & 1 & 0 & 0 & 0 & 1 & 1 & 0 & 0 & 3 \\
\hline L. abonnenci & 1 & 0 & 0 & 0 & 0 & 0 & 0 & 0 & 1 \\
\hline L. williamsi & 0 & 0 & 0 & 1 & 0 & 0 & 0 & 0 & 1 \\
\hline L. antunesi & 0 & 0 & 0 & 0 & 0 & 0 & 0 & 1 & 1 \\
\hline L. bourrouli & 0 & 0 & 0 & 0 & 0 & 1 & 0 & 0 & 1 \\
\hline Individuals Nt & & & & & & & & & 6,033 \\
\hline Species S & & & & & & 8 & & & 46 \\
\hline Diversity $\alpha$ & & 5.1 & & & & 6.3 & & & 6.8 \\
\hline $\mathrm{Nt} /$ trap nights & & & & & & 7.0 & & & - \\
\hline Dominance Nmax/Nt & & 0.2335 & & 983 & & 0.3301 & & 27 & - \\
\hline
\end{tabular}

Nt: no. specimens in sample; Nmax: no. specimens of most abundant species in sample

\section{ACKNOWLEDGEMENTS}

To the Fundação Nacional de Saúde, Macapá, particulary Dr Paulo Almeida Chavier, Director; Mr Raimundo Nonato de Anjos Freire, Chief Entomologist; Mr José Cláudio C Mendes and Mr Luiz Otávio C Nascimento, Technicians; and to the Fundação Nacional de Saúde, Unidade Mista de Porto Grande, particulary Dr José Maria Cordeiro da Silva, Director; Dr Arlene de Paiva Brandão, Chief Nurse, and Nadir Ferreira Lamião, Technician, for outstanding logistic support in Amapá.

\section{REFERENCES}

Arias JR, Freitas RA 1978. Sobre os vetores de leishmaniose cutânea na Amazônia central do Brasil. 2: incidência de flagelados em flebótomos selváticos. Acta Amazonica 8: 387 396.

Backus E, Hutchinson C, Lopez C, Miller C, Mitchel A, Moraes E, Olivieri S 1991. Biological Priorities for Conservation in Amazonia, (map with text on reverse), Conservation International, Washington, DC. 
TABLE V

Phlebotomines dissected and distribution of flagellates, Porto Grande, Amapá, November 1999

\begin{tabular}{lcccc}
\hline & \multicolumn{3}{c}{ Species ${ }^{a}$} \\
\cline { 2 - 5 } Number of females & Lutzomyia umbratilis & L. whitmani & L. spathotrichia & L. dendrophyla \\
\hline Number dissected & 211 & 6 & 3 & 14 \\
Number positive & 56 & 1 & 1 & 2 \\
Foregut + & 17 & 1 & 1 & 0 \\
Salivary glands + & 16 & 1 & 1 & 0 \\
Diverticular crop + & 0 & 0 & 0 & 0 \\
Anterior midgut + & 52 & 1 & 1 & 2 \\
Posterior midgut + & 42 & 1 & 1 & 2 \\
Pylorus + & 35 & 1 & 0 & 0 \\
Malpighian tubules + & 0 & 0 & 1 & 0 \\
Intestine + & 31 & 1 & 1 & 0 \\
\hline
\end{tabular}

a: other species dissected (all negative): L. sq. maripaensis (92), L. rorotaensis (61), L. ubiquitalis (43), L. tuberculata (23), L. paraensis (11), L. trichopyga, L. furcata (10 each), L. ayrozai (6), L. infraspinosa (4), L. scaffi (3), L. h. hirsuta, L. sericea, L. ininii (2 each), L. anduzei, L. flaviscutellata, L. y. pajoti, L. amazonensis, L. davisi, L. damascenoi, L. sordellii, Brumptomyia sp. (1 each); + : with flagellates detected in respective organ.

\section{TABLE VI}

Gonadotrophic state and distribution of flagellates in phlebotomines from which Leishmania was isolated in hamsters, Porto Grande, Amapá, November 1999

\begin{tabular}{|c|c|c|c|c|c|c|c|c|c|c|c|}
\hline \multirow{2}{*}{$\begin{array}{l}\text { Leishmania } \\
\text { isolate }^{a}\end{array}$} & \multirow[b]{2}{*}{ Host species } & \multirow[b]{2}{*}{ Parasitosis } & \multirow[b]{2}{*}{ Bloodmeal } & \multirow[b]{2}{*}{ Ovarioles } & \multicolumn{7}{|c|}{ Flagellate distribution } \\
\hline & & & & & FG & SG & AM & $\mathrm{PM}$ & PY & M T & I \\
\hline IM- $4685^{b}$ & Lutzomyia dendrophyla & ++ & Present & Medium & & & $\mathrm{X}$ & $X$ & & $\mathrm{X}$ & \\
\hline IM-4706 & L. whitmani & ++++ & Present & Medium & $X$ & $X$ & $\mathrm{X}$ & $\mathrm{X}$ & $X$ & & $y$ \\
\hline IM-4696 & L. umbratilis & ++ & Fresh & Medium & & & $X$ & $\mathrm{X}$ & & & \\
\hline IM-4687 & L. umbratilis & ++ & Absent & Large & & & & & $\mathrm{X}$ & & $\mathrm{X}$ \\
\hline IM-4733 & L. umbratilis & +++ & Present & Medium & & & $\mathrm{X}$ & $\mathrm{X}$ & & & $\mathrm{X}$ \\
\hline IM-4731 & L. umbratilis & +++ & Present & Large & & & $X$ & $\mathrm{X}$ & $X$ & & \\
\hline IM-4698 & L. umbratilis & +++ & Absent & Small & & & $\mathrm{X}$ & $\mathrm{X}$ & $\mathrm{X}$ & & \\
\hline IM-4689 & L. umbratilis & +++ & Present & Large & & & $\mathrm{X}$ & $\mathrm{X}$ & $\mathrm{X}$ & & $\mathrm{X}$ \\
\hline IM-4703 & L. umbratilis & +++ & Present & Large & & & $X$ & $\mathrm{X}$ & $\mathrm{X}$ & & $\mathrm{X}$ \\
\hline IM-4697 & L. umbratilis & +++ & Absent & Small & & & $\mathrm{X}$ & $\mathrm{X}$ & $\mathrm{X}$ & & $\mathrm{X}$ \\
\hline IM-4690 & L. umbratilis & ++++ & Present & Medium & & & $X$ & $X$ & $X$ & & $\mathrm{X}$ \\
\hline IM-4702 & L. umbratilis & ++++ & Present & Medium & & & $X$ & $X$ & $X$ & & $\mathrm{X}$ \\
\hline IM-4686 & L. umbratilis & ++++ & Present & Large & & & $X$ & $\mathrm{X}$ & $\mathrm{X}$ & & $\mathrm{X}$ \\
\hline IM-4693 & L. umbratilis & ++++ & Present & Large & & & $\mathrm{X}$ & $\mathrm{X}$ & $X$ & & $\mathrm{X}$ \\
\hline IM-4734 & L. umbratilis & ++++ & Present & Large & & & $X$ & $X$ & $X$ & & $\mathrm{X}$ \\
\hline IM-4699 & L. umbratilis & ++++ & Absent & Small & & & $X$ & $X$ & $X$ & & $\mathrm{X}$ \\
\hline IM-4745 & L. umbratilis & ++++ & Absent & Small & & & $X$ & $\mathrm{X}$ & $\mathrm{X}$ & & $\mathrm{X}$ \\
\hline IM-4701 & L. umbratilis & ++++ & Present & Large & $\mathrm{X}$ & & $X$ & $X$ & $X$ & & $\mathrm{X}$ \\
\hline IM-4710 & L. umbratilis & ++++ & Present & medium & $\mathrm{X}$ & $X$ & $X$ & $\mathrm{X}$ & $X$ & & $\mathrm{X}$ \\
\hline IM-4712 & L. umbratilis & ++++ & Present & Medium & $X$ & $X$ & $X$ & $X$ & $X$ & & $\mathrm{X}$ \\
\hline IM-4713 & L. umbratilis & ++++ & Present & Medium & $\mathrm{X}$ & $\mathrm{X}$ & $X$ & $X$ & $X$ & & $\mathrm{X}$ \\
\hline IM-4714 & L. umbratilis & ++++ & Present & Medium & $\mathrm{X}$ & $\mathrm{X}$ & $X$ & $\mathrm{X}$ & $\mathrm{X}$ & & $\mathrm{X}$ \\
\hline IM-4735 & L. umbratilis & ++++ & Present & Medium & $\mathrm{X}$ & $X$ & $\mathrm{X}$ & $\mathrm{X}$ & $X$ & & $\mathrm{X}$ \\
\hline IM-4744 & L. umbratilis & ++++ & Present & Medium & $X$ & $X$ & $X$ & $\mathrm{X}$ & $X$ & & $\mathrm{X}$ \\
\hline IM-4729 & L. umbratilis & ++++ & Present & Large & $X$ & $X$ & $X$ & $X$ & $X$ & & $\mathrm{X}$ \\
\hline IM-4732 & L. umbratilis & ++++ & Present & Large & $X$ & $X$ & $X$ & $X$ & $X$ & & $\mathrm{X}$ \\
\hline IM-4741 & L. umbratilis & ++++ & Present & Large & $X$ & $\mathrm{X}$ & $\mathrm{X}$ & $X$ & $\mathrm{X}$ & & $\mathrm{X}$ \\
\hline IM-4742 & L. umbratilis & ++++ & Absent & Medium & $X$ & $X$ & $X$ & $X$ & $X$ & & $\mathrm{X}$ \\
\hline IM-4695 & L. umbratilis & ++++ & Absent & Large & $X$ & $X$ & $X$ & $X$ & $X$ & & $\mathrm{X}$ \\
\hline IM-4715 & L. umbratilis & ++++ & Absent & Small & $X$ & $X$ & $X$ & $X$ & $X$ & & $\mathrm{X}$ \\
\hline
\end{tabular}

a: all isolates are compatible with Le. guyanensis by morphology and behaviour in hamsters; $b$ : mixed infection Leishmanial Endotrypanum by morphology in culture; FG: cephalic foregut; SG: salivary glands; AM: anterior midgut; PM: posterior midgut; PY: pylorus; MT: Malpighian tubules; I: intestine (hindgut). Parasites per field (x40 objective): ++, 6-20; +++, 21-40; ++++, > 40

Brazil RP, Andrade Filho JD, Falcão AL 2000. Notes on the phlebotomine sand flies (Diptera: Psychodidae) from Amapá State, North Brazil. J Am Mosquito Control Assoc 16: 40-41.

Christensen HA, Fairchild GB, Herrer A, Johnson CM, Young DG, Vasquez AM 1983. The ecology of cutaneous leishmaniasis in the Republic of Panama. J Med Entomol 20: 463484.
Franco AMR, Tesh RB, Guzman H, Deane M, Grimaldi Jr G 1997. Development of Endotrypanum (Kinetoplastida: Trypanosomatidae) in experimentally infected phlebotomine sand flies (Diptera: Psychodidae). J Med Entomol 34: 189192.

Killick-Kendrick R 1979. Biology of Leishmania in phlebotomine sandflies. In WHR Lumsden, DA Evans (eds), Biology of the 
Kinetoplastida, Vol. 2, Academic Press, New York, p. 395460.

Killick-Kendrick R, Killick-Kendrick M, Tang Y, Bastien P 1996. Metacyclic promastigotes of Leishmania in the salivary glands of experimentally infected phlebotomine sandflies. Parasite 3: 55-60.

Lainson R 1988. Ecological interactions in the transmission of the leishmaniases. Phil Trans R Soc Lond B 321: 389-404.

Lainson R, Shaw JJ 1973. Leishmanias and leishmaniasis of the New World, with particular reference to Brazil. PAHO Bull 7: 1-19.

Naiff RD, Freitas RA, Naiff MF, Arias JR, Barrett TV, Momen H, Grimaldi Jr G 1991. Epidemiological and nosological aspects of Leishmania naiffi Lainson \& Shaw, 1989. Mem Inst Oswaldo Cruz 86: 317-321.

Oliveira AG, Andrade Filho JD, Falcão AL, Brazil RG 2001. A new sand fly, Lutzomyia campograndensis sp. n. (Diptera: Psychodidae: Phlebotominae) from the State of Mato Grosso do Sul, Brazil. Mem Inst Oswaldo Cruz 96: 325-329.

Ryan L, Lainson R, Shaw JJ, Braga RR, Ishikawa EAY 1987.
Leishmaniasis in Brazil. XXV. Sandfly vectors of Leishmania in Pará State, Brazil. Med Vet Entomol 1: 383-395.

Schlein Y, Jacobsen RL, Messer G 1992. Leishmania infections damage the feeding mechanism of the sandfly vector and implement parasite transmission by bite. Proc Natl Acad Sci 89: 9944-9948.

Souza AAA, Barata IR, Silva MGS, Lima JAN, Martins AFP 2001. Contribuição à fauna de flebotomíneos (Diptera: Psychodidae) da Serra Navio, Amapá, Brasil. Rev Soc Bras Med Trop 34 (Supl. 1): 53.

Vivenes A, Oviedo M, Márquez JC, Montoya-Lerma J 2001. Effect of a second bloodmeal on the oesophagus colonization by Leishmania mexicana complex in Lutzomyia evansi (Diptera: Psychodidae). Mem Inst Oswaldo Cruz 96: 281283.

Young DG, Duncan MA 1994. Guide to the Identification and Geographical Distribution of Lutzomyia Sand Flies in Mexico, The West Indies, Central and South America (Diptera: Psychodidae), Memoirs of the American Entomological Institute, no. 54, Associated Publishers, Gainesville, 881 pp. 
